\title{
Editorial
}

\section{Technology and learning}

This special issue of Psicología Escolar e Educacional, published by the Brazilian Association of Educational and School Psychology, includes some expanded and revised papers presented during the IV International Conference on Multimedia and ICTs in Education (m-ICTE2006, http://www.formatex.org/micte2006), which took place at the Faculty of Communication of the University of Seville, in Spain, during 22-25 November 2006. This CISCO Systems-sponsored Conference was organized by Formatex (Badajoz, Spain), founder of this conference series in Spain, and it counted on the support of a solid group of currently active researchers in the field, which were in charge of selecting the most relevant works submitted for oral presentation and discussion at the conference. We would like to thank the work done by these members of the conference scientific advisory committee:

Ángel García del Dujo - University of Salamanca - Spain

Barney Dalgarno - Charles Sturt University - Australia

Bill Hunte - University of Ontario - Canada

Chin-Chung Tsai - Institute of Education - Chiao Tung National University- Taiwan

Daniel Burgos - Open University of the Netherlands - The Netherlands

Demetrios Sampson - Informatics Telematics Institute - Greece

Elhanan Gazit, H.I.T. - Holon Institute of Technology - Israel

Fernando de Arriaga - Polytechnic University of Madrid - Spain

Giuliana Dettori - CNR Institute of Didactic Technologies - Italy

Harold Modell - Physiology Educational Research Consortium - United States

lan Kinchin - King's College of London - University of London - United Kingdom

Joaquín Gairín Sallán - Autonomous University of Barcelona - Spain

Joseph D. Novak - Institute for Human and Machine Cognition - United States

Juan de Pablos Pons - University of Seville - Spain

Katie Goeman - Vrije University of Brussels - Belgium

Katy Campbell - University of Alberta - Canada

Manuel Area - La Laguna University - Spain

Maria Cristina Rodrigues Azevedo Joly - São Francisco University - Brasil

Marios C. Angelides - Brunel University - United Kingdom

Marius Fieschi, Marseille Medicine Faculty - France

Miguel Ángel Sicilia - University of Alcalá - Spain

Moncef Bari - Quebec and Montreal University - Canada

Roberto Carneiro - Portuguese Catholic University - Portugal

Roberto Moriyón - Autonomous University of Madrid - Spain

Silvia Gherardi - University of Trento - Italy

T. Ramayah- Sains University of Malaysia - Malaysia

Toshio Fukuda - Nagoya University - Japan

Vicki L. Cohen - Fairleigh Dickinson University - USA

Vladimir Uskov, - Bradley University - United States 
Over 450 researchers from about 50 countries participated at m-ICTE2006 Conference. In addition to most general aspects related to the application of multimedia and ICTs in Education, 5 specialized sessions, representing current hot topics, were organized:

\author{
- Multimedia and ICTs in Science Education \\ - Collaborative Learning/Groupware \\ - E-Learning Standards: Learning Objects and Repositories \\ - Digital Games \\ - National, Regional and Local Experiences
}

As it was done with previous editions, works presented at the conference, compiled in the book "Current Developments in Technology-Assisted Education (2006)", were made freely available on-line, and they can be consulted both from the Formatex and conference websites. An increasingly significant part of the conference is taking place on-line, through the virtual participation modality established. In this edition, over 50 participants chose this modality for participating at the Conference. These papers are presented and discussed on-line, and they are also archived permanently at the virtual conference section of the website (http://www.formatex.org/ micte2006/virtual/).

We are committed with favouring the conditions to make such a concentration of people sharing a common research interest as fruitful as possible from a scientific viewpoint, and in this sense, other features than the oral or poster presentations were designed. There was an opportunity to make public call for partners for all those who were attending the conference not only for presenting works but for seeking research/technology partners for advancing in their research. Those researchers had the opportunity of expose their research expertise, the kind of collaboration they were seeking and the skills the partners should have. Just a sample of some of this public calls were: Supporting Project for the Beginner Literate People in Antalya (Dr. M. Aksu, Akdeniz University, Turkey), Accessibility standards for educational multimedia products (Dr. Michela Ott, CNR, Italy), Academic Writing and Critical Thinking Supported by Electronic Media (Claire Penketh and Mark Schofield, Edge Hill University, UK), Health and Social Care Education (Dr. Marie Krumins, Centre for Inter-Professional e-Learning, Coventry University, UK), Online Study Programs in Europe (Dr. Klaus Wannemache, HIS Higher Education Information System, Germany).

The importance (while recognizing the difficulties) of interdisciplinary collaborations of more technicallyoriented researchers with more educationally or socially-oriented ones was also highlighted during the presentation of a numerous group of translational collaborative projects funded by the European Union. These are usually very good examples of active people joining for mobilizing knowledge from diverse areas in order to resolve current problems in this specific area. Some examples of these kinds of transnational projects presented were: WINDS - Web based Intelligent Design Tutoring System (http://winds.gmd.de), VELVITT - Virtual Electronic Learning in Vocational Initial Teacher Training (http://velvitt.banki.hu), MISTRAL - Measurable Intelligent and Reliable Semantic Extraction and Retrieval of Multimedia Data (http://mistral-project.tugraz.at), LeActiveMath - LanguageEnhanced, User-Adaptive, Interactive eLearning for Mathematics (http://www.leactivemath.org), ELS - European Languages Skills (http://www.eurobusinesslanguageskills.net), "La Piazza" - Convivial Spaces for Inter-generational Learning: What places for the digital age? (http://I6I./ /6.88.107/la_piazza/index.php), Up2UML - Upskilling to Object-Oriented Software Development with the Unified Modelling Language (http://www.up2uml.org), EU4ALL - European Unified Approach for Assisted Lifelong Learning (http://www.eu4all-project.eu), CIRCE - ICT on Classics (http://www.circe.be). 
As a way to maximize the visibility and impact of the conference presentations, the organizers invited a number of researchers (who presented well justified and complete research/developments works) to write up their presentations to be considered for inclusion in a journal special issue. These papers underwent peer review, revision and further review. This special issue contains those papers which were finally accepted for publication. We are very grateful to these reviewers for their collaboration throughout the process and the willingness to meet our editorial requirements: We would also like to thank the members of the conference secretariat and organization, in special to Aurora Solano, for their effort in making the conference so successful for making possible this special issue Psicología Escolar e Educacional.

Antonio Méndez-Vilas

General Coordinator of the Conference

Guest editor of the special issue

Maria Cristina Rodrigues Azevedo Joly

Psicologia Escolar e Educacional editor 